\title{
Peningkatan Pengetahuan dan Keterampilan Pembuatan "Basabokas" untuk Siswa Kelas 5 Sekolah Dasar
}

\author{
Increasing Knowledge and Skills in "Basabokas" Making \\ for $5^{\text {th }}$ Grade Students of Elementary School \\ Kartika Yuni Purwanti, Anni Malihatul Hawa \\ Universitas Ngudi Waluyo (UNW), Kabupaten Semarang \\ kartika.yuni92@gmail.com, hawa.anni@gmail.com
}

Riwayat Artikel: Dikirim 14 Februari 2019; Diterima 24 November 2019; Diterbitkan 30 November 2019

\begin{abstract}
Abstrak
Tujuan pengabdian ini yaitu peningkatan pengetahuan dan keterampilan siswa dalam pembuatan bak sampah dari botol bekas. Metode pelaksanaan yang digunakan adalah metode partisipatif dengan melalui tiga tahap yaitu 1) sosialisasi, 2) pendampingan, 3) monitoring dan evaluasi. Hasil dari pelaksanaan adalah: 1) pemahaman siswa tentang pengelolaan sampah menjadi botol bekas dalam kategori sangat baik. Hal ini ditandai dengan rata-rata persentase indikator ketercapaian sebesar 90,48\% serta peningkatan rata-rata keterampilan siswa dari 2 menjadi $3,7,2)$ memperoleh respon positif yang dilihat dari indikator kehadiran peserta mencapai 100\% dari target dan peserta antusias selama mengikuti kegiatan dari awal sampai akhir kegiatan. Kegiatan ini perlu dilaksanakan oleh selruh kelas agar seluruh siswa mampu mengetahui manfaat 3R (reuse, reduce and recycle). Kegiatan pengabdian ini diharapkan ke depan dapat sampai membuka akses pasar bagi hasil produksi (aneka kreasi daur ulang) serta dapat dilanjutkan pada tahun-tahun berikutnya di lokasi lain untuk menunjang kelestarian lingkungan dan budaya hidup sehat.
\end{abstract}

Kata kunci: basabokas, daur ulang, botol bekas

\begin{abstract}
The purpose of this service is to increase students' knowledge and skills in making trash bins from used bottles. The implementation method used is participatory method through three stages, namely 1) socialization, 2) mentoring, 3) monitoring and evaluation. The results of the implementation are: 1) students' understanding of waste management into used bottles in the excellent category. This is indicated by the average percentage of achievement indicators of $90.48 \%$ and the average increase in student skills from 2 to 3.7 , 2) obtaining a positive response as seen from the attendance indicator reaching 100\% of the target and the enthusiastic participants participating in activities from the beginning to the end of the activity. This activity needs to be carried out by the whole class so that all students are able to know the benefits of $3 \mathrm{R}$ (reuse, reduce and recycle). This community service activity is expected in the future to be able to open market access for production results (various recycled creations) and can be continued in the following years in other locations to support environmental preservation and a culture of healthy living.
\end{abstract}

Keywords: basabokas, recycled, used bottles

\section{PENDAHULUAN}

Sampah adalah suatu benda yang tidak digunakan atau tidak dikehendaki dan harus dibuang, yang dihasilkan oleh kegiatan manusia (Manik, 2007). Sampah merupakan salah satu permasalahan lingkungan yang memerlukan perhatian serius. Sampah adalah suatu bahan yang terbuang atau dibuang dari sumber hasil aktivitas manusia maupun proses alam yang belum memiliki nilai ekonomis. Sampah yang dibuang ke lingkungan dapat menjadi beban bagi lingkungan. Secara umum jenis sampah dapat dibedakan menjadi 3 (tiga), yaitu sampah organik/ basah, sampah anorganik/ kering dan smapah berbahaya (Sejati, 2009). Seiring meningkatnya jumlah penduduk maka volume sampah di lingkungan juga ikut bertambah. Keberadaan sampah dapat bersumber dari 
rumah tangga, kegiatan pertanian, kegiatan pembangunan dan pemugaran gedung, daerah perdagangan, maupun lembaga pendidikan.

Sampah di sekolah merupakan salah satu sumber sampah yang cukup besar peranannya dalam pencemaran lingkungan. Keberadaan sampah di suatu lingkungan memang tidak bisa dihindari. Keberadaan sampah dapat menimbulkan pencemaran tanah dan air, menimbulkan bau tidak sedap, menjadi sarang binatang yang merupakan sumber penyakit, serta mengganggu keindahan, namun demikian keberadaan sampah dapat dikurangi. Upaya sederhana yang dapat dilakukan untuk meminimalkan sampah adalah melakukan pemilahan antara sampah organik dan sampah anorganik. Sampah organik dapat dijadikan kompos, sedangkan sampah anorganik dapat dijadikan aneka kreasi (hasta karya) daur ulang.

Siswa SDN Lanjan 02 Kecamatan Sumowono Kabupaten Semarang, khususnya kelas 5, juga merupakan bagian dari masyarakat yang menghasilkan sampah setiap hari. Sampah sebagian besar merupakan bahan anorganik, misalnya berupa botol kaca, botol plastik, tas plastik, dan kaleng. Adanya kepedulian dari siswa dan guru untuk meminimalkan sampah tentunya sangat membantu meminimalkan timbunan sampah keseluruhan yang masuk di lingkungan sekolah.

Upaya meminimalkan sampah dapat dilakukan dengan 3R (reduce, reuse, recycle). 3R adalah prinsip utama mengelola sampah mulai dari sumbernya, melalui berbagai langkah yang mampu mengurangi jumlah sampah yang dibuang ke tempat pembuangan akhir (ESP-USAID, 2010). Upaya tersebut dilandasi pemikiran bahwa setiap orang berhak atas lingkungan yang layak dan nyaman, sehingga setiap orang wajib menjaga kenyamanan lingkungan sekolah, tanpa kecuali.

Sampah botol plastik dapat dijadikan tempat lilin, frame foto, tempat alat tulis, dompet bulat, gantungan hias, tempat tisu, celengan, lampu hias, bunga hias, hiasan tas, hiasan lemari es, anting, gelang, kalung, gantungan kunci, gantungan handphone, bando, dan bros (Prastiwi \& Widihastuti, 2010). Pelatihan pengelolaan sampah anorganik dari botol bekas menjadi tempat sampah dalam rangka meminimalkan sampah tentunya akan sangat bermanfaat, apalagi jika sampah yang telah didaur ulang menjadi aneka kreasi unik dan cantik dapat memiliki manfaat tertentu dan bernilai ekonomi sehingga dapat menambah penghasilan sekolah.

Berdasarkan uraian di atas, maka dipandang perlu untuk melakukan" Pelatihan Pembuatan "Basabokas" Bak Sampah dari Botol Bekas untuk Siswa Kelas 5 Sekolah Dasar". Pelatihan tersebut bertujuan untuk meningkatkan keterampilan siswa dalam membuat bak smapah dari botol bekas. Penulis mengambil SD Lanjan 02 karena dari hasil survey, SD tersebut merupakan sekolah yang memiliki sampah botol paling banyak, serta belum memanfaatkan sampah secara optimal. Penulis mengambil kelas 5 dengan alasan usia siswa kelas 5 sudah memasuki masa operasional konkret sehingga mereka sudah mampu mengoperasionalkan instrumen yang digunakan dalam pengabdian.

\section{METODE}

Alat dan bahan yang di persiapkan adalah botol air mineral, kawat ukuran 12 dan 14, cat avian 3 warna, thiner, lem aica aibon, kuas, tang, serta karung beras. Metode kegiatan yang dilakukan dalam pengabdian masyarakat ini adalah dengan metode partisipatif artinya mitra binaan secara aktif dilibatkan semua dalam semua tahapan kegiatan pengabdian masyarakat ini. Tahaptahap kegiatan pengabdian adalah sosialisasi, demonstrasi dan praktek pembuatan basabokas serta monitoring dan evaluasi.

Sasaran kegiatan pengabdian kepada masyarakat adalah siswa kelas 5 dengan jumlah 20 siswa. Lokasi penelitian adalah SDN Lanjan 02 Kecamatan Sumowono 
Kabupaten Semarang. Kegiatan ini menggunakan metode pelatihan yang akan dilaksanakan selama 6 bulan. Cara pembuatan basabokas, dapat digambarkan dalam gambar di bawah ini.

Gambar 1.

Proses Pembuatan Basabokas

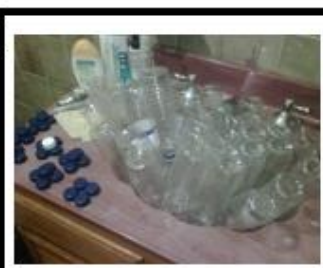

Cuci botol

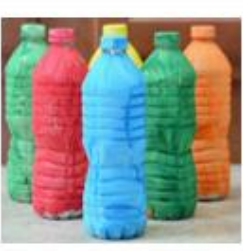

Pengecatan botol

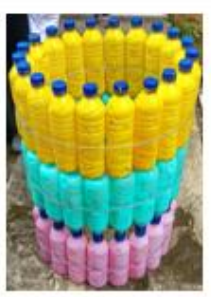

Penvatuan botol dengan rangka kaw

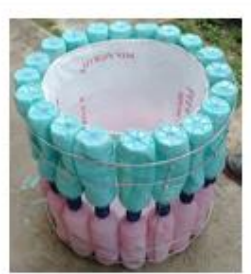

Hasil Akhir

Sumber: Dokumentasi Pribadi

Tingkat keberhasilan program ini dilakukan melalui pengamatan langsung melalui penilaian kinerja dan kemampuan peserta dalam proses memahami pengelolaan sampah anorganik menjadi aneka kreasi daur ulang, dengan mengacu pada indikator yang tercantum dalam rubrik yang telah disiapkan. Adapun model rubrik yang digunakan adalah rubrik untuk menilai keterampilan proses sebagai berikut.

Tabel 1.

Instrumen Ketercapaian Indikator

\begin{tabular}{|c|l|c|c|c|c|}
\hline \multirow{2}{*}{ No. } & \multicolumn{1}{|c|}{ Pernyataan } & \multicolumn{4}{|c|}{ Skala } \\
\cline { 3 - 6 } & 4 & 3 & 2 & 1 \\
\hline 1 & $\begin{array}{l}\text { Mengenal berbagai } \\
\text { sampah anorganik }\end{array}$ & & & & \\
\hline 2 & $\begin{array}{l}\text { Pemahaman siswa dalam } \\
\text { pengelolaan sampah }\end{array}$ & & & & \\
\hline 3 & $\begin{array}{l}\text { Pemberdayaan siswa } \\
\text { dalam pengelolaan } \\
\text { sampah anorganik }\end{array}$ & & & & \\
\hline 4 & $\begin{array}{l}\text { Pengetahuan siswa } \\
\text { tentang pengelolaan } \\
\text { sampah anorganik } \\
\text { menjadi aneka kreasi daur } \\
\text { ulang }\end{array}$ & & & & \\
\hline
\end{tabular}

Sedangkan rubrik penilaian keterampilan pembuatan basabokas terdapat dalam tabel 2 berikut.
Tabel 2.

Rubrik Keterampilan Basabokas

\begin{tabular}{|c|l|l|l|l|l|}
\hline \multirow{2}{*}{ No. } & \multicolumn{1}{|c|}{ Pernyataan } & \multicolumn{4}{|c|}{ Skala } \\
\cline { 3 - 5 } & & 4 & 3 & 2 & 1 \\
\hline 1 & $\begin{array}{l}\text { Alat dan bahan terdiri } \\
\text { dari atas botol air minera, } \\
\text { kawat ukuran 12 dan 14, } \\
\text { cat avian 3 warna, } \\
\text { thinner, lem aica aibon, } \\
\text { kuas, tang, serta karung } \\
\text { beras }\end{array}$ & & & & \\
\hline 2 & $\begin{array}{l}\text { Bentuk dan ukuran } \\
\text { basokas proporsional }\end{array}$ & & & & \\
\hline 3 & Warna menarik & & & & \\
\hline 4 & Kerapian & & & & \\
\hline
\end{tabular}

Pedoman pengkategorian terdapat dalam tabel 3 berikut.

Tabel 3

Pedoman Pengkategorian

\begin{tabular}{|c|c|c|}
\hline Rentang & Persentase & Kategori \\
\hline $13 \leq \mathrm{x} \geq 16$ & $75 \% \leq \mathrm{x} \geq 100 \%$ & Sangat baik \\
\hline $9 \leq \mathrm{x}<12$ & $50 \% \leq \mathrm{x}<75 \%$ & Baik \\
\hline $5 \leq \mathrm{x}<8$ & $25 \% \leq \mathrm{x}<50 \%$ & Cukup \\
\hline $0 \leq \mathrm{x}<4$ & $0 \% \leq \mathrm{x}<25 \%$ & Kurang baik \\
\hline
\end{tabular}

\section{HASIL DAN PEMBAHASAN}

Kegiatan pengabdian kepada masyarakat yang telah dilakukan tim pelaksana mendapat respon positif dari mitra yaitu SDN Lanjan 02. Hal ini terlihat dari siswa yang antusias mengikuti kegiatan dan hasil kegiatan juga dalam kategori sangat baik. Kegiatan ini dilakukan dengan cara tatap muka selama tiga kali pertemuan dengan 
durasi $2 \mathrm{jam} /$ pertemuan. Kegiatan pertama yaitu sosialisasi. Kegiatan pertama yaitu Sosialisasi pemanfaatan barang bekas serta

Demonstrasi Pembuatan Basabokas Kegiatan ini dilakukan oleh 3 orang tim pelaksana dengan pokok bahasan yang disampaikan adalah Sosialisasi tentang sampah organik dan anorganik, pembuangan limbah botol di masyarakat, engolahan limbah botol plastik, pemanfaatan kembali botol plastic serta demonstrasi basabokas dan pembuatannya.

Kegiatan kedua adalah praktik pembuatan basabokas. Tim pengabdian menjelaskan kembali cara pembuatan basabokas, kemudian siswa melakukan praktik secara berkelompok (1 kelas dibagi menjadi 2 kelompok). Siswa sangat antusias dalam pembuatan basabokas, terutama saat mereka mulai memberikan botol bekas dengan cat warna - warni. Dengan kreativitas yang dimiliki, botol plastik bekas warna-warni dapat dijadikan berbagai bentuk yang cantik sehingga terlihat artistik dan seperti tidak terbuat dari bahan botol plastik bekas. Dalam berkreasi dengan botol plastik bekas, terlebih dahulu botol kita bersihkan, selanjutnya botol diisi dengan menggunakan cat agar tampak warna warni, kemudian botol disusun menggunakan lem, diikat menggunakan kawat agar tampak kokoh, serta bagian dalam diberi karung sebagai tempat sampah. Kegiatan praktik ini berakhir dengan harapan agar semangat dalam mendaur ulang barang bekas terutama botol untuk dimanfaatkan menjadi barang-barang yang berguna.

Kegiatan ketiga adalah monitoring dan evaluasi (monev). Kegiatan ini mem-follow up dari kedua kegiatan yang telah dilakukan sebelumnya. Siswa memanfaatkan basabokas sebagai tempat sampah. Mereka membuang sampah pada basabokas dengan penuh antusias. Hasil ketiga kegiatan yang telah dilakukan menunjukkan peningkatan pemahaman yang dimiliki peserta kegiatan yang berjumlah 21 orang. Peningkatan tersebut dapat terlihat pada persentase pemahaman sebelum dilakukannya kegiatan pengabdian kepada masyarakat dan setelah dilakukannya kegiatan pengabdian kepada masyarakat yang dapat terlihat pada Gambar 2.

Gambar 2.

Peningkatan Pemahaman Siswa

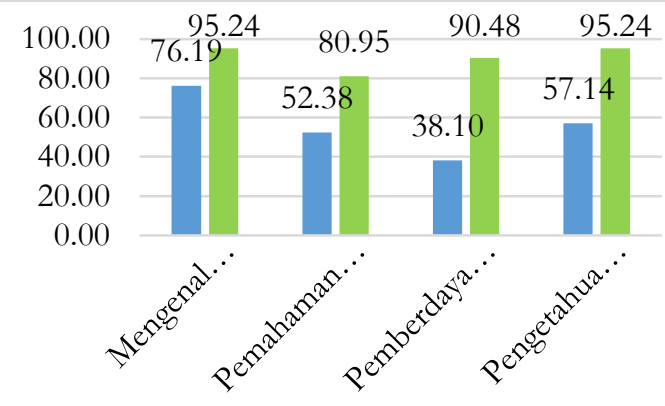

Sumber: Data primer yang diolah

Berdasarkan Gambar 2, peserta kegiatan telah mengalami peningkatan pemanfaatan barang bekas dengan rata-rata 90,48\%, yaitu mengenal berbagai sampah anorganik $95,24 \%$, pemahaman siswa tentang pengelolaan sampah sebesar 80,95\%, pemberdayaan siswa dalam pengelolaan sampah anorganik $90,48 \%$ serta pengetahuan siswa tentang pengelolaan sampah anorganik menjadi aneka kreasi daur ulang 95,24\%. Oleh karena itu, hasil kegiatan pelatihan pembuatan basabokas ini dapat dikatakan berhasil dalam kategori sangat baik.

Hasil peningkatan keterampilan siswa dalam membuat basabokas terdapat dalam tabel 3 berikut.

Tabel 4.

Peningkatan Keterampilan Siswa

\begin{tabular}{|c|c|c|c|c|c|}
\hline \multirow{2}{*}{ No. } & \multirow{2}{*}{ Pernyataan } & \multicolumn{2}{|c|}{ Kel 1} & \multicolumn{2}{|c|}{ Kel 2} \\
\hline & & Pre & Pos & Pre & Pos \\
\hline 1 & $\begin{array}{l}\text { Kesiapan alat dan } \\
\text { bahan }\end{array}$ & 2 & 4 & 2 & 4 \\
\hline 2 & $\begin{array}{l}\text { Proses pengecatan dan } \\
\text { penyatuan }\end{array}$ & 2 & 3 & 2 & 4 \\
\hline 3 & Warna menarik & 2 & 4 & 2 & 3 \\
\hline 4 & Bentuk proporsional & 2 & 4 & 2 & 4 \\
\hline 5 & Kerapian & 2 & 4 & 2 & 3 \\
\hline & Rata-rata & 3 & 3,8 & 2 & 3,6 \\
\hline
\end{tabular}

Tabel 4 menunjuukkan skor perolehan keetrampilan siswa dalam membuat basabokas. Keterampilan siswa dalam pembuatan basabokas meningkat, terlihat bahwa rata-rata keterampilan siswa baik 
kelompok 1 maupun kelompok 2 meningkat. Tabel juga menunjukkan bahwa rata-rata keterampilan kelompok 1 lebih tinggi dari kelompok 2. Rata-rata akhir keterampilan siswa meningkat dari 2 menjadi 3,7.

Pelaksanaan program pengabdian di SDN Lanjan 02 Kecamatan Sumowono Kabupaten Semarang berjalan dengan baik. Program pengabdian berupa pelatihan pengelolaan botol bekas menjadi bak sampah perlu terus diupayakan mengingat produksi sampah semakin banyak dan didukung rendahnya kesadaran 3R, yaitu reuse (memakai kembali barang bekas yang masih bisa dipakai), reduce (berusaha mengurangi sampah), dan recycle (mendaur ulang sampah agar dapat dimanfaatkan). 3R merupakan prinsip utama mengelola sampah mulai dari sumbernya, melalui berbagai langkah yang mampu mengurangi jumlah sampah yang dibuang ke tempat pembuangan akhir (ESP-USAID, 2010). Hal ini menjadi pertimbangan bagi Tim Pengabdian untuk mencari cara yang tepat dalam mengelola sampah anorganik sehingga tidak mencemari lingkungan, tetapi justru mampu memberikan keuntungan bagi masyarakat, yaitu dengan menjadikan sampah anorganik (botol plastik bekas) menjadi bak sampah. Manfaat yang dapat diperoleh para peserta pelatihan adalah memahami pengelolaan sampah anorganik menjadi aneka kreasi daur ulang sehingga dapat turut serta dalam menjaga kelestarian lingkungan di sekitarnya.

\section{KESIMPULAN}

Berdasarkan uraian pada hasil dan pembahasan di atas, maka dapat disimpulkan sebagai berikut.

1. Pelatihan pengelolaan botol bekas menjadi tempat sampah di lokasi pengabdian dapat meningkatkan pengetahuan siswa tentang pengelolaan sampah anorganik menjadi aneka kreasi daur ulang serta memberdayakan mereka dalam pengelolaan sampah anorganik (botol plastik bekas) menjadi bak sampah.

2. Terdapat eningkatan keterampilan siswa dalam membuat bak sampah dari botol bekas. Terbukti bahwa rata-rata keterampilan siswa meningkat.

3. Peningkatan pengetahuan bagi peserta pelatihan tentang kesadaran 3R, yaitu reuse (memakai kembali barang bekas yang masih bisa dipakai), reduce (berusaha mengurangi sampah), dan recycle (mendaur ulang sampah agar dapat dimanfaatkan).

\section{DAFTAR PUSTAKA}

ESP-USAID. (2010). Modul Pelatihan Pengelolaan Sampah Berbasis Masyarakat. Jakarta: Environmental Services Program.

Manik, K. E. S. (2007). Pengelolaan Lingkungan Hidup. Jakarta: Penerbit Djambatan.

Prastiwi, K. W. \& Widihastuti, Y. (2010). Recycle Bottle: Ragam Kreasi Limbah Botol Plastik. Surabaya: Tiara Aksa.

Sejati, K. (2009). Pengolahan Sampab Terpadu. Yogyakarta: Kanisius. 